\title{
PICASSO EN ITALIA, 1917
}

\section{PICASSO IN ITALY, 1917}

Pablo Miguel Salazar Jiménez (Universidad de Málaga, España) pablomsj97@hotmail.com

$$
\text { Recibido: } 04 \text { junio } 2021 \text { / Aceptado: } 25 \text { agosto } 2021
$$

Resumen: En 1917, Italia le presenta a Pablo Picasso (1881-1973) la oportunidad de inaugurar una nueva etapa artística en la que pervivirá y se modificará el cubismo y, al mismo tiempo, van tomando lugar los elementos del clasicismo de carácter ingresco. Al trabajar durante esta estancia italiana para los Ballets Russes en el telón y vestuario de la obra Parade, pudo perfeccionar su conocimiento de la tradición de la Commedia dell'Arte y retomar la iconografía de Arlequín. En Roma, visita y aprecia los tesoros de la ciudad, como el Coliseo iluminado o la Capilla Sixtina y, en sus paseos por Campania, quedó prendado por los frescos y las ruinas de Pompeya y Herculano que le inspiraron toda una serie de dibujos. Además de monumentos clásicos y obras maestras del Renacimiento, encontró en unas postales de una vendedora de flores con el traje tradicional el punto de partida para elaborar la imagen de la mujer italiana como muestra del aprendizaje adquirido en este país. Será en la Città Eterna donde conocerá a su futura mujer, la bailarina Olga Khokhlova, con la que comenzará una nueva etapa personal.

Palabras clave: Picasso; Italia; Ballets Rusos; Arlequín.

Abstract: In 1917, Italy presented Pablo Picasso (1881-1973) with the opportunity to inaugurate a new artistic stage in which Cubism would survive and be modified, while at the same time, the elements of Ingresque classicism would take place. Working during this Italian stay for the Ballets Russes on the curtain and costumes for the work Parade, he was able to perfect his knowledge of the tradition of the Commedia dell'Arte and take up again the iconography of Harlequin. In Rome, he visited and appreciated the treasures of the city, such as the illuminated Colosseum or the Sistine Chapel and, during his walks in Campania, he was captivated by the frescoes and ruins of Pompeii and Herculaneum, which inspired a whole series of drawings. In addition to classical monuments and Renaissance masterpieces, he found in some postcards of a flower seller in traditional costume the starting point to elaborate the image of the Italian woman as a sample of the learning acquired in this country. It will be in the Città Eterna where he will meet his future wife, the ballerina Olga Khokhlova, with whom he will begin a new personal stage.

Keywords: Picasso; Italy; Ballets Russes; Harlequin 
Cómo citar este artículo:

Salazar Jiménez, P. (2021). Picasso en Italia, 1917. Revista Eviterna 10, 106-116 / DOI:

https://doi.org/10.24310/Eviternare.vi10.12836

\section{Introducción}

La primera experiencia de Pablo Picasso en Italia tuvo lugar en 1917, año en el que se seguía librando la Primera Guerra Mundial. El ambicioso y joven poeta Jean Cocteau deseaba que Serguéi Diáguilev pusiera en escena su ballet Parade en París, pero Misia Sert intentó echar por tierra el proyecto. Sin embargo, Eugenia Errázuriz, la protectora y mecenas chilena de Picasso, logró convencer a Diághilev para que aceptara, siempre que el artista malagueño se encargase del decorado, Erik Satie de la partitura y Léonide Massine de la coreografía. Los decorados, el vestuario y los ensayos se harían en Roma, donde el empresario de los Ballets Russes tenía su cuartel general en tiempos de guerra. Tras dos años y medio de contienda, Picasso estaba eufórico ante la oportunidad de poder dejar atrás los bombardeos y apagones para pasar un par de meses en Roma, ciudad que siempre había querido visitar (Richardson, 2007, p. 3).

\section{2. «L'oiseau du Bénin à Rome»}

Picasso y Cocteau llegaron a Roma el 19 de febrero, un día más tarde de lo previsto (Richardson, 2007, p. 3). Se instalaron en el grand hôtel de Russie, ubicado en la via del Babuino, entre la piazza del Popolo y la piazza di Spagna (Cabanne, 1982, p. 295). Es en este lugar donde Picasso saluda a la luz de Italia, aunque en el mes de febrero no haya alcanzado aún su culminación. Desde la ventana de su estudio alquilado en el 53B de la via Margutta, lo primero que le impresiona de esta nueva ciudad es la silueta de la villa Medici, que no tarda en plasmar en distintas ocasiones desde el mismo punto de vista. Este complejo arquitectónico del siglo XVI, cuyos jardines inmortalizó Velázquez hacia 1630, es la sede de la Academia Francesa de Roma desde 1803, de la que Ingres fue director entre 1835 y 1840. En un primer momento, Picasso esboza su estructura con el lápiz de un modo muy lineal y esquemático ${ }^{1}$ para permitir en dibujos posteriores que entren en escena los colores y envuelvan al edificio en una malla puntillista, quizás para indicar un día lluvioso² (Carandente, 1998, p. 38). Atraído por la gran maestría con la que Corot captó la luz dorada de Roma y la Campagna, Picasso dota a la fachada ocre de una masa etérea y brillante con estas acuarelas puntillistas, de manera que pueda parecer en algunos casos irreal. Precisamente son estos toques de irrealidad que aparecen en la villa Medici los que ayudan a reconocerla, a recordarla y, en definitiva, a fijar su imagen (Palau, 1999, p. 19).

\footnotetext{
${ }^{1}$ OPP.17:028; OPP.17:038; OPP.17:214-215; OPP.17:217; OPP.17:328; OPP.17:476.

2 OPP.17:039; OPP.17:044.
} 
La primera noche que pasó Picasso en la ciudad pudo observar el Coliseo iluminado, denominándolo Cocteau como «that enormous reservoir of the centuries, which one would like to see come alive, crowded with people and wild beasts and peanut vendors» ${ }^{3}$ (Richardson, 2007, p. 4). El poeta será el encargado de dibujar a Picasso en la ciudad italiana, de perfil, con el ojo levemente cubierto por su característico mechón de pelo y una pipa entre los labios, enviándole el retrato al poeta Guillaume Apollinaire con el título «L'oiseau du Bénin à Rome», apodo con el que se refería al artista malagueño. De la misma manera, Picasso realiza un dibujo de Cocteau ${ }^{4}$ ataviado con una bata de pliegues verticales y oblicuos, entendida por Pierre Cabanne (1982, p. 295) como una obra de transición entre los dibujos cubistas y el denominado como «período ingresco», asegurando el propio retratado que se trata del primer ejemplo de una serie importante. Paralelamente, se divertía elaborando rápidos estudios de retratos y caricaturas de otros miembros de la compañía como Diághilev, Massine o Léon Bakst ${ }^{5}$, así como un par de autorretratos cómicos ${ }^{6}$.

«Je n'oublierai jamais l'atelier de Rome»` (Cocteau, 1997, p. 103), escribirá Cocteau sobre el estudio en el que Picasso confeccionó una maqueta de la escenografía de Parade en la que poder ensayar las distintas variantes de su idea original. El efecto debió resultar demasiado estático, pues Picasso se fue al extremo opuesto y puso en marcha un diseño en el que confluyese el teatro futurista con la tradición de las nuevas representaciones circenses, teniendo en mente obras como Parade de cirque (1887-88) de Seurat. Los proyectos para el telón de fondo ${ }^{9}$ incluyen elementos cubistas que serán sustituidos en el telón de boca ${ }^{10}$ por una representación figurativa naturalista, introduciendo a un grupo de siete personajes ante un fondo de bambalinas de teatro. A la izquierda, una acróbata se balancea sobre una yegua blanca que porta las alas de Pegaso, mientras que Arlequín, torero, pareja de amantes, marinero y acróbata completan la escena de una manera plana, pero con destacados contornos (Warncke, [1992] 2002, p. 253).

Del mismo modo, Picasso trabajará insistentemente en el vestuario de Parade, recordando Cocteau que «On lui monte des œufs et du fromage romain, il refuse de sortir quand la peinture le posséde» ${ }^{11}$ (Léal, 1998, p. 56). Los bocetos que elaboró se conservan, en su mayor parte, en el Musée Picasso de París como hojas separadas, pero fueron realizados originalmente en cuadernos de dibujos adquiridos en Italia, ya que aparece una filigrana en cada hoja en la que se puede leer «P. M. Fabriano» y «Enrico Magnani Pescia» (Léal, 1998, p. 60). El pequeño Carnet 19 es el único que ha sobrevivido, conteniendo una veintena de estudios

\footnotetext{
3 «Ese enorme depósito de los siglos que uno quisiera ver cobrar vida, atestado de gente y de bestias salvajes y de vendedores de cacahuetes»; carta de Cocteau enviada a su madre el 20 de febrero de 1917.

${ }^{4}$ OPP.17:104.

5 OPP.17:093-097; OPP.17:103; OPP.17:114; OPP.17:204-205; OPP.17:208-210; OPP.17:239; OPP.17:300;

OPP.17:463; OPP.17:477; OPP.17:488.

6 OPP.17:206-207.

${ }^{7}$ «Nunca olvidaré el taller de Roma».

8 OPP.17:219.

${ }^{9}$ OPP.17:045; OPP.17:047-052.

10 OPP.17:010.

11 «Hace que le traigan huevos y queso romano, se niega a salir cuando la pintura lo posee».
} 
que arrojan luz sobre la evolución de los personajes de Parade. Menos elaborados que la mayoría de los dibujos separados, estos bocetos son reflejo del desarrollo del proyecto, observándose cómo la cabeza del caballo de madera ${ }^{12}$ no había alcanzado aún el agresivo fuselaje y deslumbrante cromatismo de su estado definitivo.

Los estudios del manager a caballo ${ }^{13}$ son tanto más interesantes cuanto que no existe ningún otro rastro de este personaje, eliminado del ballet por haberse caído de su montura durante el ensayo general. Concebido originalmente como un jinete de carne y hueso, algo así como un vaquero o, según Brigitte Léal (1998, p. 56), una posible caricatura de Diághilev, Picasso lo imaginó cabalgando sobre su montura, masticando un puro y luciendo un ostentoso atuendo de music hall compuesto por sombrero de copa y frac. Su montura era un caballo de lona, maniobrado por dos bailarines ocultos bajo la tela, parodiando las entradas que realizaban los payasos en el circo. El manager francés y su colega americano servían a la vez como piezas de arquitectura desvinculadas del decorado y como esculturas móviles que podían ser desplazadas por los actores, funcionando como verdaderos socios de la acción en la misma medida que la niña americana o el prestidigitador chino.

Pese a las declaraciones contradictorias ofrecidas por el propio Picasso, encontró tiempo para visitar la Capilla Sixtina y las Stanze de Rafael en el Vaticano. Ernest Ansermet, director de orquesta de Diághilev, afirma haber escuchado a Picasso y a Ígor Stravinsky hablar con mucho entusiasmo de los frescos de Miguel Ángel. Stravinsky llegó a Roma el 5 de abril, congeniando al instante con Picasso en tanto que se convirtieron en amigos para toda la vida (Richardson, 2007, p. 23). Picasso le comentó al compositor que tenía poco oído para la música, pero un sentido inherente del ritmo, lo que le permitía apreciar los logros de «the greatest rhythmic thinker since Beethoven ${ }^{14}$ (Walsh, 1999, p. 41). Jean-Paul Crespelle recuerda lo siguiente:

He worked on his sets in the midst of the company's rehearsals in the great hall of the Palazzo Theodoli on the Piazza Colona where Diaghilev was living, and every evening a small council consisting of Cocteau, Diaghilev and Massine examined the models he had designed during the day. In spite of his work, he found time to visit the Sistine Chapel and the Vatican to see the work of Michelangelo and Raphael ... Through Raphael he returned to the Ingres manner. Michel George-Michel, who was with Diaghilev at the time, has told of his enthusiasm which led him to say: 'Da Vinci promises heaven ... But Raphael provides it' ${ }^{15}$ (Crespelle, 1969, p. 119).

Cocteau confirma esta visita a los Museos Vaticanos, alegando que Rafael no había revolucionado la percepción de la gente de forma tan radical como lo había hecho Picasso. En

\footnotetext{
12 OPP.17:355-356.

13 OPP.17:357-358.

14 «El mayor pensador rítmico desde Beethoven».

15 «Trabajaba en sus decorados en medio de los ensayos de la compañía en la gran sala del Palazzo Theodoli, en la Piazza Colona, donde vivía Diághilev, y todas las noches un pequeño consejo formado por Cocteau, Diághilev y Massine examinaba las maquetas que había diseñado durante el día. A pesar de su trabajo, encontró tiempo para visitar la Capilla Sixtina y el Vaticano para ver la obra de Miguel Ángel y Rafael... A través de Rafael volvió a la manera de Ingres. Michel George-Michel, que estaba entonces con Diághilev, ha contado su entusiasmo, que le llevó a decir: "Da Vinci promete el cielo... pero Rafael lo proporciona"».
} 
cuanto a Miguel Ángel, el poeta lo define como un maravilloso dibujante, pero un mal pintor (Richardson, 2007, p. 18). La negativa de Picasso sobre que nunca había visitado este lugar pudo deberse a un intento de evitar citar a Rafael como influencia, una elección académica y presumible. Como figura fundamental del arte moderno que derrocó toda la tradición renacentista, Picasso no habría querido reconocer deuda alguna con sus fundadores. Sin embargo, dos años más tarde, pintaría una respuesta a La donna velata ${ }^{16}$ (1515) para demostrar que podía realizar una tela a la altura del maestro de Urbino, obra que en ningún momento tuvo la intención de vender ni de exponer en vida del artista.

Durante los ensayos de la compañía, Picasso conoció a una bailarina. De origen aristocrático e hija del coronel ruso Stepán Khokholov, Olga se incorporó a la troupe como bailarina en 1911, independizándose de su familia con tan sólo diecinueve años. Pese a que comenzó tardíamente, muestra grandes dotes para la danza, apareciendo su nombre en multitud de programas y viajando con la compañía por Europa y Norteamérica (Eliacheff, 2019, p. 275). Fue en la Città Eterna, con veintiséis años, cuando conoció a su futuro marido. Por su parte, Picasso, diez años mayor que ella, todavía sufría de chagrin d'amour por Irène Lagut, con quien debía casarse justo antes de conocer a Olga, y no se opone a la idea de fundar una familia. Para explicarle al artista la resistencia de la joven ante sus proposiciones, tanto Diághilev como Bakst le advirtieron que «con una rusa, jhay que casarse!» (Widmaier Picasso, 2003, p. 63).

Para Michael C. FitzGerald (1996, p. 303), el primer retrato de Olga de perfil ${ }^{17}$ destaca por la atención obsesiva del artista y el distanciamiento de la modelo. Picasso presenta a Olga con una proximidad íntima que se difumina por su pose hierática, esbozando su blusa abierta y el pelo ondulado como marco para sus ojos y la línea nítida del perfil que se desvanece en el mentón. Sigue la tradición del retrato de camafeo, con una pose reforzada por un contorno nítido y un bajo relieve, teniendo como peculiaridad que es el único retrato de Olga que se conserva con una inscripción que incluye el nombre del artista en cirílico (Пикассо) (FitzGerald, 1996, p. 304). Dicho retrato está dibujado a lápiz en una hoja doble de papel con membrete del hôtel Minerva de Roma, donde la bailarina se alojaba. Además, adjunta a la hoja había una tarjeta postal con la reproducción del retrato de Beatrice Cenci, una obra atribuida en aquel momento a Guido Reni ${ }^{18}$. El cuadro formaba parte de la colección del palazzo Barberini, por lo que Picasso y Cocteau pudieron contemplar esta pintura que sirvió de fuente de inspiración para autores como Stendhal, Antonin Artaud o Alejandro Dumas (Carandente, 1998, p. 37).

Picasso, además de realizar el vestuario y los decorados de Parade, produjo una serie de obras inspiradas en su estancia italiana. Un motivo que le atraerá son las imágenes de las vendedoras de flores de la piazza di Spagna. Para ello, no buscó inspiración en los monumentos clásicos ni en las obras maestras del Renacimiento, sino en el kitsch turístico.

\footnotetext{
16 OPP.19:022.

17 OPP.17:105.

18 En la actualidad, la obra es atribuida a Ginevra Cantofoli (Bolonia, 1618-1672), pintora italiana del Barroco.
} 
Unas postales de colores estridentes que representaban a estas vendedoras de flores vistiendo el traje tradicional de ciociaria fueron el punto de partida para elaborar toda una serie sobre $L^{\prime} /$ talienne à la fleur ${ }^{19}$. El poeta Josep Palau i Fabre (1999, p. 18) determina que estas obras son producto de la interacción de la postal y la visión directa de la propia vendedora de flores, debido a las distintas versiones que realizó el artista. En el brazo izquierdo transporta una cesta de mimbre en la que deposita sus flores, que apenas se logran ver, ya que es la propia florista la que ha quedado repleta de atributos florales. Con ello, Picasso hace una crítica del realismo severo, que nunca podría transmitir la alegría de esta muchacha. El artista quiere dejar muestra de su paso por Italia trazando a la mujer del país, entendiendo este gesto más que como un homenaje como una muestra del conocimiento y profundización de este lugar.

En la acuarela titulada L'italienne ${ }^{20}$, el artista emplea pequeños toques de pincel en sentido horizontal con una sutil curvatura, cubriendo una zona pintada inicialmente del mismo color, pero con una entonación más pálida para que así resalten estos toques. Sólo en algunas franjas se observan toques mezclados de colores diferentes, jugando de una manera mucho más llamativa. El fondo previo rojo, azul o verde crea unas superficies más homogéneas que anuncian la solidez y la construcción por planos aislados del lienzo L'Italienne ${ }^{21}$. En esta ocasión, la silueta de la basilica di San Pietro se encuentra a su lado para que no quede ninguna duda sobre su filiación. Se funden el lenguaje cubista y la representatividad tradicional para dar lugar, según Palau (1999, p. 39), a la «representatividad inteligible de una manera inmediata». El lienzo está realizado con colores brillantes que recogen la alegría del arte popular italiano que tanta influencia está ejerciendo en estas obras, observándose además la representación simultánea de dos puntos de vista, el perfil azul de la muchacha se coloca como una máscara lúdica frente a la imagen rosada del rostro. L'Italienne remite a los grandes cuadros cubistas de mujeres que sostienen guitarras o mandolinas, portando en este caso una cesta de mimbre colgada del brazo como la que apoya en su regazo L'Italienne de Derain ${ }^{22}$ del invierno de 1909.

En incontables ocasiones, la historiografía picassiana ha puesto en valor el modo en que Parade no sólo significó una vuelta a la fascinación de Picasso por Arlequín, sino que se convirtió para el artista en la ocasión idónea para perfeccionar su conocimiento de la tradición de la Commedia dell'Arte. Lo que se discute menos, como apuntó Yve-Alain Bois (2008, p. 22), es que no hay rastro alguno de Arlequín en el libreto ideado por Cocteau, hasta tal punto de no aparecer el personaje en el ballet. La única presencia en el escenario se encuentra en el enorme telón de boca, obra que, como señaló Elizabeth Cowling (2002, p. 299), sólo estaría a la vista durante unos minutos en cada representación mientras se interpretaba la obertura de Satie. En definitiva, Picasso sentía que necesitaba a Arlequín en este momento, aunque nada en el ballet pudiera justificar la presencia de este personaje. Por ello, Picasso realizó un gouache

${ }^{19}$ OPP.17:037; OPP.17:040-043; OPP.17:265; OPP.17:267; OPP.17:274; OPP.17:436-437; OPP.17:459; OPP.17:474.

20 OPP.17:015.

${ }^{21}$ OPP.17:117.

22 OPP.09:115. 
sobre una tabla de madera ${ }^{23}$ en el que representa a un Arlequín de apariencia rígida, invitando a pensar en una posible influencia del Pinocchio de Carlo Collodi, ya que la oscilación del personaje también guarda relación con los movimientos dislocados de los títeres movidos por hilos. Gracias a este encuentro con la cultura popular italiana, una de las fuentes de inspiración para Parade vino del Teatro dei Piccoli, un teatro de marionetas que Picasso y Cocteau visitaron poco después de su llegada a Roma.

La gran obra romana de Picasso es Arlequin et femme au collier ${ }^{24}$, composición de dos metros por dos que forma parte de la colección del Centre Georges Pompidou de París. Siguiendo la estela del cubismo sintético de Juan Gris, en este lienzo se disponen únicamente formas geométricas planas, resolviendo el conjunto cromático de una manera sobria al emplear azul, gris, negro y blanco, contrastando con las obras luminosas que realizaron los futuristas en aquel momento. De hecho, en el caffè Greco (Leymarie, 1990, p. 74) coincide con algunos de los artistas alistados en las filas del futurismo, como Enrico Prampolini, Fortunato Depero o Giacoma Balla, así como Filippo Tommaso Marinetti, su principal promotor intelectual. La pareja del lienzo se presenta separada y al mismo tiempo enlazada, configurando una escena en la que se confronta lo masculino y lo femenino. La movilidad del personaje femenino encuentra su fundamento en las piernas cruzadas, convirtiéndose en el elemento más inestable de todo el conjunto, mientras que sus pechos apuntan de una manera agresiva hacia Arlequín. El problema de la inestabilidad ya se encuentra presente en las couples de danseurs ${ }^{25}$ de 1915-1916, al igual que el Arlequin ${ }^{26}$ de 1915 podría asociarse como precedente. Resulta llamativa la figura que se encuentra bajo el personaje de la Commedia dell'Arte, que algunos autores como Palau (1999, p. 40) o John Richardson (2007, p. 14) han denominado «homúnculo», surgiendo de un diminuto proscenio. Las grandes dimensiones de la obra y el hecho de haber sido fotografiado delante de este cuadro, sugiere que para Picasso significaba una declaración importante, una respuesta al impacto de Roma. Gino Severini, a quien Picasso mostró su pintura, informa sobre la misma:

Sopratutto una grande tela fatta in uno spirito molto lineare, forme a due dimensioni, di una limpidezza esterna, trattate quasi in nero e bianco. Questo quadro, di una poesia pittorica giunta al massimo della trasposizione e dalla astrazione era intitolato "Marchere" ed era inspirato, secondo quanto mi disse Picasso stesso, alla purezza di contorno e di forma d'Ingres. L'influenza dei Musei italiani egli preferí subirla filtrata attraverso Ingres $^{27}$ (Severini, 1968, pp. 15-20).

\footnotetext{
23 OPP.17:118.

24 OPP.17:002.

25 OPP.15:004; OPP.15:098; OPP.15:101-104; OPP.16:137; OPP.15:159.

26 OPP.15:001.

27 «Sobre todo, un gran lienzo realizado con un espíritu muy lineal, formas bidimensionales, de una claridad exterior, tratadas casi en blanco y negro. Este cuadro, de una poética pictórica que llega al máximo de la transposición y la abstracción, se titulaba «Marchere» y se inspiraba, según me dijo el propio Picasso, en la pureza de contorno y de forma de Ingres. La influencia de los museos italianos a los que prefería someterse se filtró a través de Ingres».
} 


\section{3. «Moi / Hôtel Vesuvio / Naples / chambre / 114»}

El 9 de marzo, aprovechando un fin de semana de descanso de la compañía, Diághilev lleva a Picasso, Cocteau y Massine a Nápoles, alojándose en el grand hôtel du Vesuve. Es posible que esta visita obedezca al deseo de ver los frescos y las ruinas de Pompeya y Herculano, pues el día 12 de marzo, que era lunes, están de regreso en Roma. La vestimenta formal compuesta por sombrero de fieltro, cuellos de camisa y polainas no impidió que el artista, el poeta y el bailarín se paseasen sobre las columnas y las ruinas de la Antigüedad, informando Massine que Cocteau había traído una cámara y fotografió a todos los miembros apoyados en estatuas y bloques rotos de mármol (Massine, 1968, p. 108). El 16 de abril volvieron en tren a Nápoles para una estancia algo más larga. Esta vez les acompañaron Stravinsky y Ansermet en lugar de Cocteau. Durante el trayecto, Picasso aceptó un reto que consistía en realizar un retrato de Massine en menos de cinco minutos si el bamboleo del tren se lo permitía, consiguiéndolo y entregándole el dibujo al retratado ${ }^{28}$.

Viajaron junto a la compañía, que había sido contratada para una corta temporada, del 21 al 23 de abril, en el teatro di San Carlo, el gran teatro de ópera de la ciudad. La temporada sería un desastre, recibiendo los ballets, especialmente Les femmes de bonne humeur, unas críticas tan terribles que hubo que cancelar las tres últimas representaciones de las cinco previstas (Richardson, 2007, p. 25). De nuevo, se alojaron en el grand hôtel du Vesuve, apuntando Picasso en el cuaderno italiano «moi / Hôtel Vesuvio / Naples / chambre / 114», mientras Olga se hospedó en el hôtel Vittoria con las otras bailarinas, pero ese motivo no hizo que Picasso cesase de frecuentar prostíbulos, recogiendo en el Carnet 19 la dirección de un burdel napolitano (Léal, 1998, p. 55).

En Nápoles, al igual que en Roma, el trío de Parade se deleitaba con el entretenimiento popular, sobre todo con la tradicional Commedia dell'Arte en el barrio de Forcella. Estos espectáculos callejeros hacía tiempo que quedaron obsoletos, aunque en Nápoles se mantuvo viva la tradición, destacando en sus representaciones la violencia y las numerosas payasadas obscenas que distan de las amables arlequinadas de los dibujos de Giovanni Domenico Tiepolo. Massine convenció a uno de los de los actores para que le vendiese su antigua máscara de cuero, que siempre llevaba para su papel de Pulcinella (Richardson, 2007, p. 26). El coreógrafo propuso elaborar un verdadero ballet de Commedia dell'Arte, algo que nunca se había intentado, aprobando la idea tanto Diághilev como Picasso y Stravinsky. Mientras estaban en Nápoles, trabajaron en un escenario y realizaron la investigación necesaria en el museo di san Martino.

El museo di san Martino, situado en una cartuja del siglo XVII en la colina del Vomero, es célebre por su espectacular colección de presepios, muy apreciados por los turistas, pero Picasso y Massine habían visitado este lugar para estudiar todo lo relativo a la Commedia dell'Arte, especialmente las máscaras de Pulcinella, marionetas y otros elementos de la cultura popular napolitana. En esta visita, Picasso compró estampas de las acuarelas del pintor italiano

28 OPP.17:244. 
Achille Vianelli que representan escenas de la vida popular napolitana, estampas que tras la muerte de Picasso se descubrieron dentro de un cuaderno de dibujos italiano. Las Scene popolari di Napoli de Vianelli, como La Taverna, con el Vesubio al fondo, tiene un parecido tan sorprendente con la sección central del rideau rouge de Parade que a menudo se cita como inspiración de la composición de Picasso (Bignardi, 2017, p. 29). Sin embargo, Richardson (2007, p. 27) afirma que el artista había decidido su diseño meses antes de viajar a Italia y que pudo comprar las postales porque una de las acuarelas era similar a su escena entre bastidores. Otros recuerdos del viaje napolitano de Picasso fueron una máscara antigua de Pulcinella como la de Massine y un par de marionetas que acabarían encima del piano de Olga. Estos objetos serían de gran ayuda en 1920, cuando Picasso comenzó a trabajar en Pulcinella, el ballet de la Commedia dell'Arte que Nápoles había inspirado.

Una serie de garabatos fálicos recogidos en el Carnet 19 y una carta a Gertrude Stein sobre sus «fantaisies pompeyennes», actualmente en la Beinecke Library, revelan que Picasso visitó el gabinetto segreto del museo archeologico nazionale di Napoli, donde se guardan la mayoría de los artefactos eróticos de Pompeya y Herculano. A mediados de los años cincuenta, cuando Picasso regaló a la artista Barbara Hiles Bagenal uno de estos dibujos por Navidad ${ }^{29}$, le confirmó que los temas habían sido sugeridos por los frescos eróticos de Nápoles (Richardson, 2007, p. 27). Estos dibujos se inspiran en pinturas murales descubiertas en las villas romanas de parejas apolíneas y fiestas báquicas, al igual que los frescos de Tiepolo en las villas venecianas del Ottocento.

Para Picasso, la mayor revelación de Nápoles fue la magnífica Colección Farnesio de esculturas monumentales de la Antigüedad grecorromana, atractivo principal del museo nazionale. De todas las piezas que formaban parte de la colección, fue el Hércules Farnesio, una copia romana de una escultura en bronce de la segunda mitad del siglo IV a. C. atribuida a Lisipo, la que dejó una huella más profunda en el devenir artístico de Picasso, sobre todo en su sentido de la monumentalidad. El tamaño de Hércules, que se eleva por encima de los demás colosos de la colección, sobrecogió a Picasso y se sintió especialmente fascinado por los sutiles ajustes de escala, evidentes en el aumento de los párpados y los dedos, así como el ensanchamiento del puente de la nariz, modificaciones que habían permitido al escultor dotar a su figura de tanta monumentalidad y, del mismo modo, de tanto carácter y patetismo.

Picasso regresó a Roma el 22 de abril y permaneció allí alrededor de una semana, viajando el 28 o 29 de abril a Florencia para reunirse con Olga y el resto de la compañía, donde iban a dar una única función nocturna el lunes 30 de abril en el teatro Massimo. Olga bailó en tres de los cinco ballets del programa. Alberto Magnelli, que había participado de forma marginal en los preparativos de Parade, llevó a Picasso a visitar los museos, iglesias y palacios de Florencia. No especifica qué le interesaba a Picasso más allá de mencionar a los «primitivos», probablemente en la galleria degli Uffizi, y las esculturas de Miguel Ángel

29 OPP.17:258. 
pertenecientes a la decoración de la sagrestia nuova de basilica di san Lorenzo, que más tarde dejarían huella en su obra.

\section{Conclusiones}

Picasso no estuvo más de diez semanas en Italia, volviendo a Montrouge en mayo para enseñarle su apartamento del número 22 de la rue Victor-Hugo a Olga, con la que se casará al año siguiente. Podemos concluir que este viaje por Italia significó para Picasso la reconciliación con la figuración realista y la tradición clásica de los grandes maestros del Renacimiento italiano, sin abandonar el cubismo sintético que lo proclamó como fundador del arte moderno. Resultado de la evocación napolitana, comienza a trabajar en la década de 1920 sobre figuras olímpicas de carácter monumental que visten un camisón recordando a los peplos de grandes pliegues que cubren los mármoles griegos, planteando el carácter escultórico de sus obras. Queda como prototipo Deux femmes courant sur la plage (La course $)^{30}$, gouache sobre madera contrachapada en el que las figuras monumentales matizan el carácter de lo clásico como rasgo de la mediterraneidad. A su vez, ese interés por los trabajos que representaban la vida popular italiana y las obras maestras del Cinquecento generará una impronta que estará presente a lo largo de toda su obra, surgiendo en sus últimos años una serie de grabados de la Suite 347 protagonizados por un joven y lujurioso Rafael haciendo el amor con la Fornarina. A partir de esta experiencia italiana, su vida personal y, sobre todo su vida artística, asumirán una nueva dirección.

\section{Recursos bibliográficos}

Bignardi, M. (2017). Picasso a Napoli: una "Montmartre arabe". Nápoles: Liguori.

Bois, Y. A. (2008). Picasso the Trickster. En Bois, Y. A. (Ed.). Picasso harlequin: 1917-1937 (pp. 19-35). Milán: Skira.

Cabanne, P. (1982). El siglo de Picasso. Vol. I: El nacimiento del Cubismo; Las metamorfosis (1881-1937). Madrid: Ministerio de Cultura.

Carandente, G. (1998). Picasso and the Italian scene. En Clair, J. y Michel, O. (Eds.). Picasso: the italian journey 1917-1924 (pp. 31-48). Londres : Thames and Hudson.

Cocteau, J. (1997). Entre Picasso et Radiguet. París: Hermann.

Cowling, E. (2002). Picasso: Style and Meaning. Londres: Phaidon.

Crespelle, J. P. (1969). Picasso and his women. Nueva York: Coward-McCann.

Eliacheff, C. (2019). Las vidas de Olga. En Philippot, É., Pissarro, J. y Ruiz-Picasso, B. (Dir.). Olga Picasso (pp. 275-279). Málaga: Museo Picasso.

\footnotetext{
${ }^{30}$ OPP.22:001
} 
FitzGerald, M. C. (1996). The modernists' dilemma: neoclassicism and the portrayal of Olga Khokhlova. En Rubin, W. (Ed.). Picasso and portraiture: representation and transformation (pp. 296-335). Nueva York: The Museum of Modern Art.

Léal, B. (1998). "moi / Hôtel Vesuvio / Naples / chambre / 114" : (Picasso's Italian carnets). En Clair, J. y Michel, O. (Eds.). Picasso: the italian journey 1917-1924 (pp. 55-60). Londres: Thames and Hudson.

Leymarie, J. (1990). L'avventura italiana di Picasso. En Cortenova, G. y Leymarie J. (Eds.). Picasso in Italia (pp. 71-77). Milán: Mazzotta.

Mallen, E. (Ed.). (1997-2021). Online Picasso Project. Sam Houston State University. Recuperado de (4 de junio, 2021): https://picasso.shsu.edu/index.php

Massine, L. (1968). My life in ballet. Londres: Macmillan.

Palau i Fabre, J. (1999). Picasso: de los ballets al drama, 1917-1926. Barcelona: Polígrafa.

Richardson, J. (2007). A life of Picasso: the triumphant years, 1917-1932. Nueva York: Alfred A. Knopf.

Severini, G. (1968). Il tempo de l'Effort Moderne. Florencia: Enrico Vallechi.

Walsh, S. (1999). Stravinsky: A Creative Spring: Russia and France 1882-1934. Nueva York: Knopf.

Warncke, C. P. [1992] (2002). Pablo Picasso: 1881-1973. Colonia: Taschen.

Widmaier Picasso, O. (2003). Picasso: retratos de familia. Madrid: Algaba. 